\title{
Addition of Lead (Pb)-Nitrate Filler on Polymer Composite Aprons for X-Ray Radiation Shielding
}

\author{
E. Afrianti ${ }^{1 *}$, D. Tahir ${ }^{1}$, B. Y. E. B. Jumpeno ${ }^{2}$, O. A. Firmansyah ${ }^{2}$, J. Mellawati ${ }^{2}$ \\ ${ }^{I}$ Department of Physics, Hasanuddin University, Tamalanrea, Jl. Perintis Kemerdekaan KM. 10, Makassar 90245, Indonesia \\ ${ }^{2}$ Center for Technology of Radiation Safety and Metrology, National Nuclear Energy Agency (BATAN), \\ Jl. Lebak Bulus Raya No. 49, Jakarta 12440, Indonesia
}

\section{ARTICLE INFO}

Article history:

Received 26 February 2020

Received in revised form 15 February 2021

Accepted 16 April 2021

Keywords:

Polymer Apron

Filler

$\mathrm{Pb}$-nitrate

Effectiveness

Tensile Strength

\begin{abstract}
A B S T R A C T
Radiation shielding aprons are needed by radiation workers to minimize radiation exposure to the body. The aprons at present use fabric-coated lead plates which are heavy and rigid materials and therefore are not comfortable to use. Polymer aprons from cassava starch and glycerin with addition of $\mathrm{Pb}$-nitrate filler at $0 \%, 2 \%, 4 \%$, and $6 \%$ have been synthesized. Mixtures for synthesizing the polymer apron composites were heated using a magnetic stirrer at a speed of $800 \mathrm{rpm}$ at $160{ }^{\circ} \mathrm{C}$ for 25 minutes. Then, the polymer apron composites were dried in an oven for 24 hours at $70{ }^{\circ} \mathrm{C}$. The effectiveness of the apron was determined by calculating the attenuation coefficient $(\mu)$, half-value layer (HVL), and radiation absorption. The mechanical properties of the aprons were characterized by testing their tensile strengths using an A\&D MCT-2150 universal tester. The result shows that the optimal addition of $\mathrm{Pb}$-nitrate filler of as much as $6 \%$ produced aprons with an attenuation coefficient of $1248 \mathrm{~cm}^{-1}$, HVL of $0.54 \mathrm{~cm}$, and radiation absorption of $25 \%$, while the aprons' tensile strength was obtained as $28.244 \mathrm{MPa}$. The addition of $\mathrm{Pb}$-nitrate as a filler in apron composites proportionally improves the quality of materials used as radiation shields. More detailed research is still needed to obtain the best apron.
\end{abstract}

(C) 2021 Atom Indonesia. All rights reserved

\section{INTRODUCTION}

The contributions of nuclear technology have substantially increased in such areas as the production of electricity by nuclear power plants, environment, radiotherapy, and diagnostics in medicine, as well as applications in agriculture and various other industries [1,2]. In the health sector, nuclear technology is applied as ionizing radiation in the form of X-ray radiation for diagnosing diseases in the human body and radiotherapy treatments [3]. Besides having benefits, ionizing radiation can also be very dangerous. Interaction of radiation with matter in the human body causes cells in the body to be damaged, and excessive radiation exposure may cause cancer in humans $[4,5]$. The possible effects of ionizing radiation require strong radiation protection efforts. Therefore, radiation shielding is needed to minimize radiation exposure to the human body [6].

\footnotetext{
*Corresponding author.

E-mail address: afriantievi20@gmail.com

DOI: https://doi.org/10.17146/aij.2021.1033
}

Radiation shielding is a device used to block or absorb radiation. To absorb certain types of radiation, radiation shielding material must have a high density and high atomic number [7-9]. Radiation workers commonly wear radiation shielding in the form of aprons. The existing apron is made of a pure lead plate, making it heavy, hard, stiff, and therefore not very comfortable to wear [10]. Some of the research use composite materials from polymers as shielding radiation. Composite materials are becoming increasingly popular in a wide range of applications due to considerable results that can be achieved by combining a polymer material with various functional fillers $[8,11]$. The fillers commonly used are lead, tungsten, barium, bismuth, and various other substances [8,12,13].

Starch is one of the most promising materials for the future because it is a renewable natural polymer material that is environmentally friendly and can be modified for various purposes, including for the biomedical field. The availability of starch is quite abundant and the price is relatively low. Unfortunately, the development of starch-based 
products is limited, among other reasons, by their low tensile strength and high water vapor permeability [14]. This is related to starch's hydrophilicity and sensitivity to high water content, and this characteristic is unfortunately difficult to control [14]. Usually, one of the main components of starch-based materials is the plasticizer, which is used to reduce the brittleness due to high intermolecular forces. Water and glycerols are often used as plasticizers to produce materials from starch [14].

In this study, apron polymers were synthesized from a mixture of cassava starch, glycerin, distilled water, and $\mathrm{Pb}$-nitrate as filler. The apron synthesized is expected to be a radiation shielding that is easy to process, lightweight, and capable of absorbing radiation, especially $\mathrm{X}$-ray radiation.

\section{METHODOLOGY}

\section{Materials and instruments}

In this study, the materials used were cassava starch, $\mathrm{Pb}$-nitrate, glycerin, and distilled water. The instruments used are X-ray equipment and detectors, Tensile Testing Machine of MCT-2150 series, ovens, magnetic stirrers, beaker glass, measuring tubes, Ohaus balance, spoons, Petri dishes, and glass spatulas.

\section{Procedure}

\section{Synthesis of composite polymer apron}

Composite polymer aprons are made by mixing cassava starch, $\mathrm{Pb}$-nitrate, and distilled water into beaker glass. Then, the mixture was heated using magnetic stirrer with a speed of $800 \mathrm{rpm}$ and at a temperature of $160{ }^{\circ} \mathrm{C}$ for 5 minutes. Then, glycerin was added and the mixture reheated for 25 minutes. After the composite thickened, it was then poured into a petri dish and dried using an oven at $70{ }^{\circ} \mathrm{C}$ for 24 hours. The Pb-nitrate concentration of the synthesized composites was varied at $0,2,4$, and $6 \%$.

\section{Absorption effectiveness test of apron composite using $X$-rays}

Composite apron synthesis results were tested using X-ray radiation to determine the effectiveness of absorption (Fig. 1). Testing was conducted at a distance of $25 \mathrm{~cm}$ from the $\mathrm{X}$-ray equipment (focal spot). The distance between the X-ray equipment and the detector is $100 \mathrm{~cm}$. Furthermore, the X-ray equipment is given a voltage of $80 \mathrm{kV}$ [3].



Fig. 1. Testing using X-ray equipment.

\section{Calculation of effectiveness}

The effectiveness of apron composites is measured by calculating the value of the attenuation coefficient, half-value layer (HVL), and composite's radiation absorption. The attenuation coefficient reprsents the reduction in radiation intensity after passing through the material, while HVL is the thickness of the material needed to reduce the radiation intensity to half of the initial intensity. Calculation of effectiveness begins with calculation of attenuation coefficient, following Eq. (1) [15]:

$$
\mu=\frac{1}{x} \ln \frac{I_{0}}{I}
$$

where:

$I=$ intensity of the radiation transmitted ( $\mu \mathrm{Gy} / \mathrm{min}$.)

$I_{0}=$ intensity of radiation without absorber

$(\mu \mathrm{Gy} / \mathrm{min}$.)

$\mu=$ linear attenuation coefficient of radiation $\left(\mathrm{cm}^{-1}\right)$

$x=$ thickness of shield $(\mathrm{cm})$

The relation between $\mu$ and HVL can be stated as in Eq. (2).

$$
H V L=\frac{0.693}{\mu}
$$

The radiation absorption of the composites can be determined by Eq. (3)

$$
D S=\left(1-e^{-\mu x}\right) \times 100 \%
$$

In Eq. (3), DS represents the absorption of the shielding $(\%)$.

\section{Tensile strength test}

Tensile strength is one of the mechanical properties of the apron. In this research, a tensile strength test was carried out of the sample using an A\&D MCT-2150 universal tester.

\section{RESULTS AND DISCUSSION The effect of $\mathrm{Pb}$-nitrate filler addition on the attenuation coefficient and HVL of composite apron}

The attenuation coefficient represents the reduction in radiation intensity after passing 
through a compound or material caused by photon absorption or scattering of photons from X-rays. The attenuation coefficient attained is linear in respect to $\mathrm{Pb}$-nitrate content, which means more concentration of $\mathrm{Pb}$-nitrate that was added proportionally increased the attenuation produced (Fig. 2). Attenuation shows the effectiveness of radiation shielding; the higher the attenuation, the better the capacity to reduce radiation intensity.

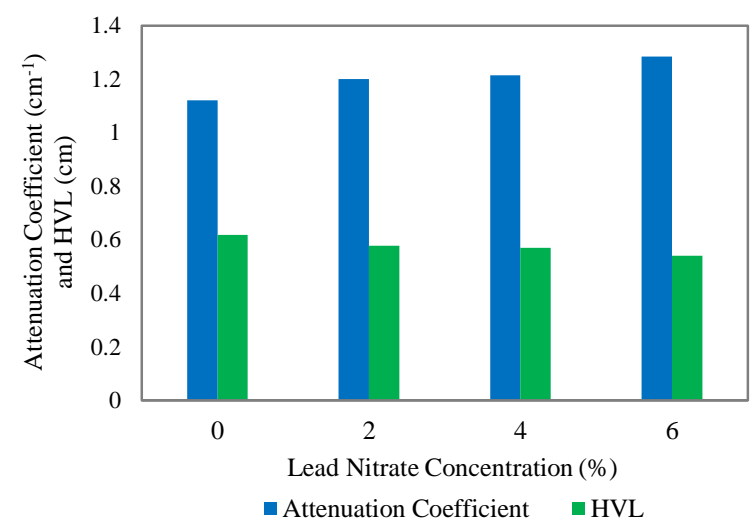

Fig. 2. The effect of various filler (Pb-nitrate) additions on attenuation coefficient and HVL.

The 0-6 \% addition of Pb-nitrate filler produces a change in the half-value layer from $0.618 \mathrm{~cm}$ to $0.540 \mathrm{~cm}$ (Fig. 2). Thus, it can be said that the smaller the HVL value, the more effective a material's capacity to block radiation. Half-value layer is usually used to assess the effectiveness of a material as radiation shielding. An HVL is the material thickness value needed to reduce the intensity of an X-ray beam to half of the initial intensity [16].

The same addition of 0-6\% $\mathrm{Pb}$-nitrate filler also changes the attenuation coefficient at $80 \mathrm{kV}$ from $1.121 \mathrm{~cm}^{-1}$ to $1.284 \mathrm{~cm}^{-1}$ (Fig. 2). A similar study using a $6 \%$ silicone rubber silica composite was conducted by Astuti et al. (2019), and the attenuation coefficient at $80 \mathrm{kV}$ was found to be $0.7 \mathrm{~cm}^{-1}[17]$.

\section{The effect of Pb-nitrate filler addition on radiation intensity of composites apron}

Increasing the addition of $\mathrm{Pb}$-nitrate in the apron composite will decrease the intensity of radiation reaching the detector (Fig. 3). This shows that the apron composite with high $\mathrm{Pb}$-nitrate filler minimizes the intensity of the transmitted radiation. Radiation protection materials with high atomic number materials will be able to absorb or withstand radiation intensity. Lead $(\mathrm{Pb})$ is an element that has high atomic number and mass density $\left(Z=82\right.$, mass density $\left.=11.34 \mathrm{~g} \mathrm{~cm}^{-3}\right)$, so the composite that is made can act as a radiation shielding.

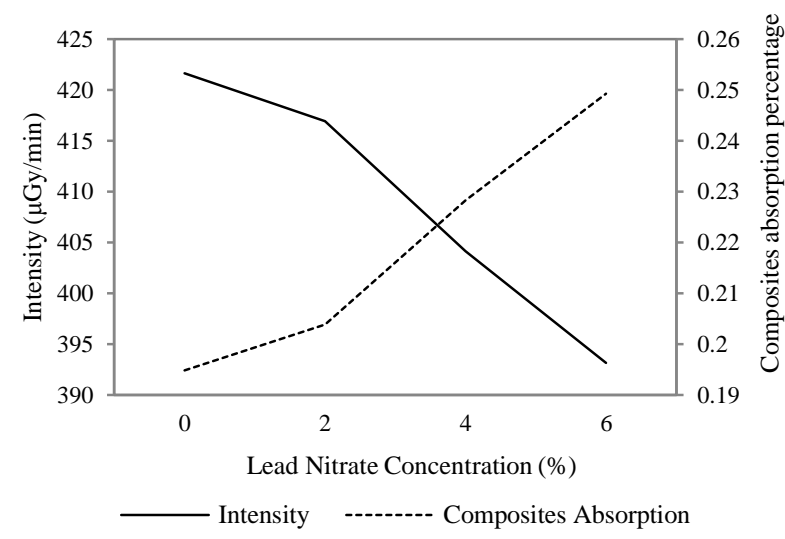

Fig. 3. The effect of various filler ( $\mathrm{Pb}$-nitrate) additions on radiation intensity and composites absorption.

Absorption capacity shows how much an apron composite can absorb radiation intensity. Figure 3 shows the effect of filler addition ( $\mathrm{Pb}$-nitrate) on radiation intensity and composite absorption. As seen in the graph (Fig. 3), as $\mathrm{Pb}$-nitrate concentration increases in the apron composite, the composite absorption capacity increases. That means the composite with $6 \%$ $\mathrm{Pb}$-nitrate filler can absorb higher radiation intensity compared with composites with $\mathrm{Pb}$-nitrate below $6 \%$. This result occurred due to the influence of the composite material which has a higher atomic number. Wozniak et al. (2017) state that heavy metals (with high atomic numbers), such as lead $(\mathrm{Pb})$, tungsten, bismuth, or a mixture of these substances, have been conventionally used to protect from X-rays due to their higher density that enables them to absorb X-ray radiation [18].

\section{The effect of Pb-nitrate filler addition on the composite thickness on radiation absorption of apron}

The thickness of the composite also affects the intensity of the transmitted radiation. The greater the thickness of the composite, the lower the intensity of the transmitted radiation. Figure 4 shows that with the increase of the polymer apron composite thickness, the transmitted radiation intensity decreases.

The increased thickness of the composite increases the radiation absorption (Fig. 4). The results showed that the addition of $6 \% \mathrm{~Pb}$ nitrate filler with a thickness of $0.6 \mathrm{~cm}$ gave the highest composite absorption value. Research by Fontainha et al. (2016) on nanocomposites showed that the addition of as much as $10 \%$ of $\mathrm{ZrO}_{2}$ filler at 
a thickness of $1 \mathrm{~mm}$ was able to absorb X-rays by $60 \%$, compared to $5 \%$ filler; this shows attenuation as a function of thickness [19].

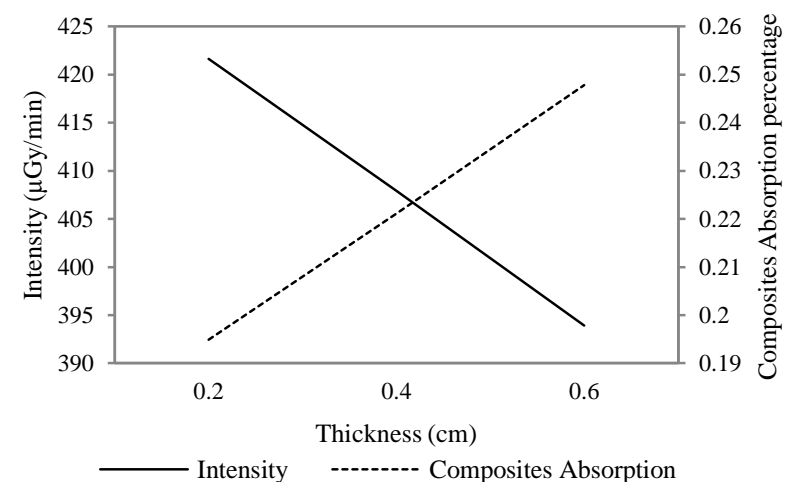

(a)



(b)

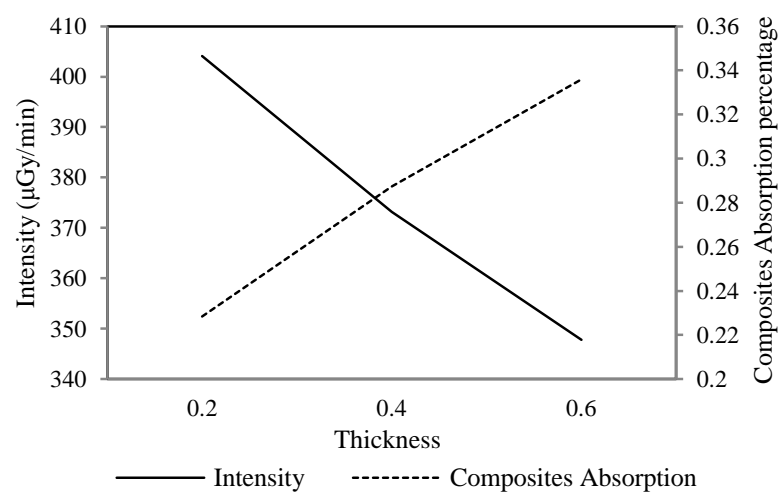

(c)

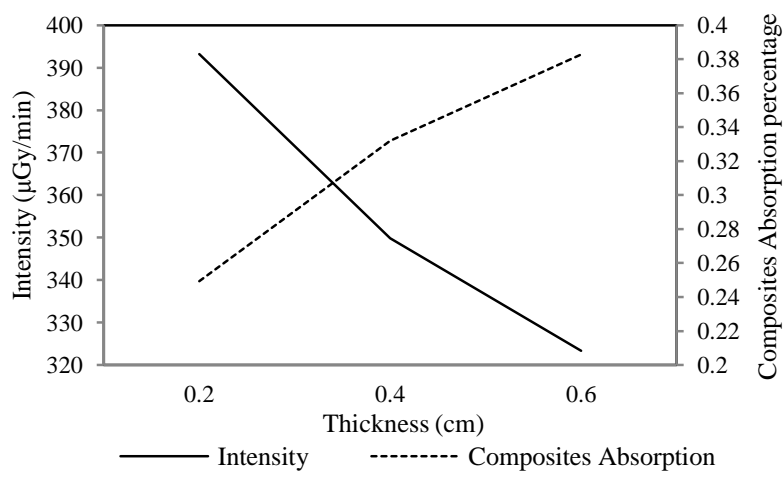

(d)

Fig. 4. The effect of composite thickness on radiation intensity and composites absorption for additional $\mathrm{Pb}$-nitrate contents of (a) $0 \%$, (b) $2 \%$, (c) $4 \%$, and (d) $6 \%$.

\section{Effect of Pb-nitrate filler addition on tensile strength of apron composite}

Tensile strength is one of the mechanical properties of the apron polymer composite. The results showed that the higher the addition of $\mathrm{Pb}$-nitrate filler concentration, the higher the tensile strength (Fig. 5).

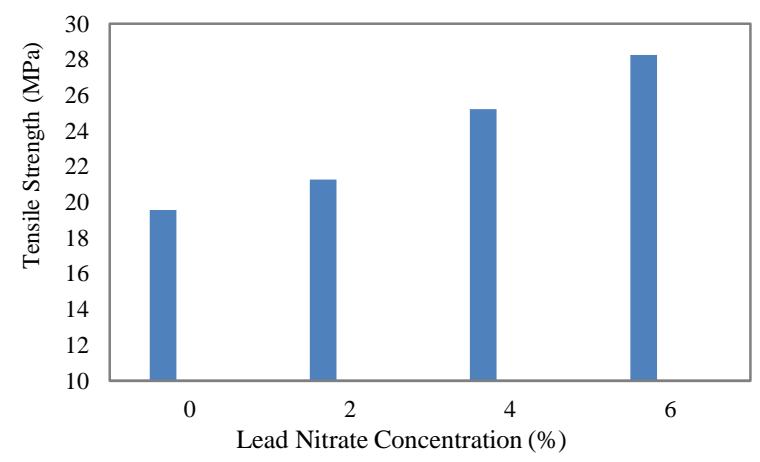

Fig. 5. The effect of various filler ( $\mathrm{Pb}$-nitrate) additions on tensile strength of polymer composite aprons.

Figure 5 shows that there is a tendency that the addition of $\mathrm{Pb}$-nitrate filler to the composite synthesis apron is able to increase its tensile strength. The addition of $\mathrm{Pb}$-nitrate filler up to $6 \%$ obtained the maximum tensile strength in the apron composite of $28.244 \mathrm{MPa}$. According to El-Kameesy et al. (2015), the addition of filler to the rubber composite also affects tensile strength, and adding $\mathrm{Pb}$-oxide filler to rubber composites can increase tensile strength by up to $35 \%$ [20].

\section{CONCLUSION}

In this study, an evaluation of the shielding properties of $\mathrm{x}$-ray radiation such as attenuation coefficient, HVL value, and absorption effectiveness of apron polymer composites made of tapioca starch with different $\mathrm{Pb}$-nitrate filler concentrations was carried out. The addition of Pb-nitrate filler on (mechanical properties) was seen to increase tensile strength with increasing filler addition. Likewise, the value of the attenuation coefficient, HVL, and the effectiveness of absorption is directly proportional to the addition of $\mathrm{Pb}$-nitrate filler. This is related to the tendency of adding fillers to the apron compound of tapioca starch which causes a linear increase in the hardness of the material. More detailed research is still needed in order to obtain optimal results.

\section{ACKNOWLEDGMENT}

The authors would like to thank Dr. Abarrul Ikram as the head of the Center for Technology of 
Radiation Safety and Metrology (PTKMR), National Nuclear Energy Agency of Indonesia (BATAN), Mr. Untara, and Mr. Kusdiana who have given permission to the author, for facilities and assistance received to conduct this research.

\section{AUTHOR CONTRIBUTION}

The first author, E. Afrianti, and the fifth author, J. Mellawati, equally contributed as the main contributors of this paper. All authors read and approved the final version of the paper.

\section{REFERENCES}

1. E. Salama, A. Maher and G. M. Youssef, J. Phys. Chem. Solids 131 (2019) 139.

2. M. Dogra, K. J. Singh, K. Kaur et al., Univers. J. Phys. Appl. 11 (2017) 190.

3. N. Aral, F. B. Nergis and C. Candan, Text Res. J. 86 (2015) 803.

4. Nurhasmi, D. Tahir, B. Abdullah et al., Mater. Sci. Forum 966 (2019) 41.

5. L. Seenappa, H. C. Manjunatha, B. M. Chandrika et al., J. Radiat. Prot. Res. 42 (2017) 26.

6. H. O. Tekin and O. Kilicoglu, J. Alloys Compd. 815 (2020) 152484.

7. T. Singh, A. Kaur, J. Sharma et al., Eng. Sci. Technol. Int. J. 21 (2018) 1078.
8. N. Cherkashina, V. Gavrish and T. Chayka, Materials Today: Proceedings 11 (2019) 554.

9. O. L. Tashlykov, S. Y. Shcheklein, V. Y. Lukyanenko et al, Nucl. Energy Technol. 2 (2016) 42.

10. S. Johansen, I. H. R. Hauge, P. Hogg et al, J. Med. Imaging Radiat. Sci. 49 (2018) 201.

11. V. Barsukov, I. Senyk, O. Kryukova et al., Material Today: Proceedings 5 (2018) 15909.

12. H. M. Soylu, F. Y. Lambrecht and O. A. Ershoz, J. Radioanal. Nucl. Chem. 305 (2015) 529.

13. Y. Elmahroug, M. Almatari, M. I. Sayyed et al., J. Non-Cryst. Solids 499 (2018) 32.

14. A. C. Souza, R. Benze, E. S. Ferrão et al., LWT Food Sci. Technol. 46 (2012) 110.

15. M. I. Sayyed, S. A. M. Issa and H. O. Teki, Mater. Chem. Phys. 217 (2018) 11.

16. A. S. Ouda and H. A. Abdel-Gawwad, HBRC Journal 13 (2017) 255.

17. S. Y. Astuti, H. Sutanto, G. W. Jaya et al., J. Phys.: Conf. Ser. 1217 (2019) 012016.

18. A. I. Wozniak, V. S. Ivanov, O. A. Zhdanovich et al., Orient. J. Chem. 33 (2017) 2148.

19. C. C. P. Fontainha, A. T. Baptista Neto, A. Pinheiro Santos et al., Mater. Res. 19 (2016) 426.

20. S. U. El-Kameesy, D. E. El-Nashar, S. El-Fiki et al., Int. J. Adv. Res. 3 (2015) 1017. 